\title{
The Synthesis of Brominated Tetrafluoro[2.2]paracyclophanes
}

\author{
Lidija Bondarenko, ${ }^{[a]}$ Jeff W. Kampf, ${ }^{[b]}$ and Jörg Lahann* ${ }^{* a]}$
}

\author{
Dedicated to Professor Henning Hopf
}

Keywords: Bridge-fluorinated [2.2]paracyclophanes / Electrophilic substitution / Structure elucidation

The bromination of the two isomeric tetrafluoro[2.2]paracyclophanes was investigated under various conditions. We found selective conditions for mono- and dibromination of 1,1,9,9-tetrafluoro[2.2]paracyclophane in high yields. Furthermore, three tetrabromo isomers were characterized.
The para-dibromide of 1,1,10,10-tetrafluoro[2.2]paracyclophane was prepared in high yields.

( Wiley-VCH Verlag GmbH \& Co. KGaA, 69451 Weinheim, Germany, 2006)

\section{Introduction}

Over the past 50 years, the chemistry and application of [2.2]paracyclophane (1) was comprehensively investigated. ${ }^{[1]}$ However, the bridge-fluorinated analogues 2, 3, 4 only became accessible in the last decade in amounts that allowed exploring its chemical and physical properties as well as its possible use in polymer science. Dolbier and co-workers ${ }^{[2]}$ improved the synthesis of octafluoro[2.2]paracyclophane (2), which made possible the systematical investigation ${ }^{[3]}$ of its chemical reactivity (Scheme 1).

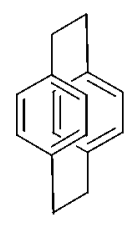

1

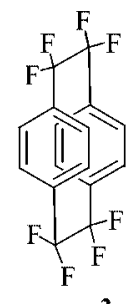

2
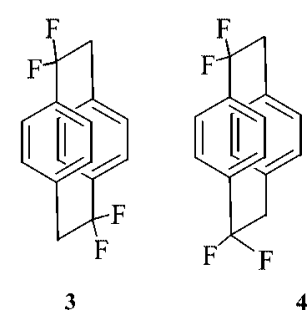

Scheme 1. Chemical structure of [2.2]paracyclophane (1), the octafluorinated [2.2]paracyclophane 2, and the tetrafluro[2.2]paracyclophanes $\mathbf{3}$ and $\mathbf{4}$.

Much less is known about the two tetrafluoro[2.2]paracyclophenes 3 and $\mathbf{4}$. They have been prepared by benzylic bromination $^{[4 \mathrm{a}]}$ of [2.2]paracyclophane to give the two isomers of tetrabromo[2.2]paracyclophane, which were separated by repeated crystallization and chromatography of the

[a] Department of Chemical Engineering, University of Michigan, 2300 Hayward, Ann Arbor, MI 48109, USA

Fax: +1-734-763-0459

E-mail: lahann@umich.edu

[b] Department of Chemistry, University of Michigan, 930 North University,

Ann Arbor, MI 48109-1055, USA filtrates. The exchange of fluorine with $\mathrm{AgBF}_{4}$ as described in the literature ${ }^{[4 \mathrm{~b}]}$ results in the pure tetrafluoro isomers 3 and 4 . Both isomers have a pleasant musk smell. The synthesis of cyclophane $\mathbf{3}$ is known also in patents, ${ }^{[5]}$ as well as in the chemical vapor polymerization (CVD) of its dichloro derivative. ${ }^{[6]}$ However, there are no systematical investigations of the chemical reactivity of cyclophane 3 .

The cyclophanes $\mathbf{1}$ and $\mathbf{2}$ are fully symmetrical molecules, but differ in their chemical reactivity. The octafluoro[2.2]paracyclophane $\mathbf{2}$ behaves as a deactivated aromatic system because of the fluoralkyl substituents at the bridge position. Nitration is the only electrophilic aromatic substitution reaction that afforded products. ${ }^{[3 a, 3 b]}$ Under harsh conditions, this reaction resulted in mono- and di-substituted derivatives, which have been successfully transformed into other functionalities.

The 1,1,9,9-tetrafluoro[2.2]paracyclophane (3) has an asymmetrical bridge, where one carbon atom bears two hydrogen atoms and the other one two electronegative fluorine atoms, thus making it possibly more reactive. Because of inductive effects, each benzene ring of the cyclophane unit is asymmetrically polarized. Therefore, the investigation of its chemical reactivity would be of special interest. We estimated that the reactivity of the aromatic ring will be between of those of cyclophanes $\mathbf{1}$ and $\mathbf{2}$, and the substitutions should occur at the position next to the bridge carbon atom that carries hydrogen atoms.

The 1,1,10,10-tetrafluoro[2.2]paracyclophane shows the same polarization of the asymmetrical bridge carbon atoms, but differs in the arrangement of the bridge atoms. One benzene ring has two para-difluoromethylene carbon atoms, which decreases its reactivity, and makes it more similar to theose in cyclophane 2 . But the other benzene ring with the para-methylene carbon atoms should have the same reactivity as that of cyclophane $\mathbf{1}$. 
We started with the Friedel-Crafts acylation reaction of cyclophane 3 with trifluoroacetic anhydride, and, in contrast to the inert cyclophane 2 , the reaction resulted in complete polymerization in spite of the very careful choice of equimolar ratio of reagents. Lowering the reaction temperature only decreased the reaction rate without any trace of products; indicating high bridge reactivity. The bridge opening of cyclophane 1 by influence of $\mathrm{AlCl}_{3}$, resulting in several rearrangement products, was observed by Cram and co-workers. ${ }^{[7]}$

The chlorination of cyclophane $\mathbf{3}$ is known in the presence of iron catalyst. ${ }^{[6 b, 6 \mathrm{~d}]}$ However, the aromatic chlorides are not so reactive towards further transformations. Therefore, we considered that the bromination of TFPC (tetrafluorooparacyclophane) would be useful, because the aromatic bromides can be transformed into many different functional groups. ${ }^{[8]}$

\section{Results and Discussion}

The bromination of cyclophane $\mathbf{1}$ is well investigated, ${ }^{[9,12]}$ and varying the reaction conditions can result in monobromide as well as pseudo-para- and pseudo-meta-substituted products with very little para and pseudo-ortho-dibromides. Tri- and tetrabromides are all pseudo-para or pseudo-ortho isomers. In contrast, bromination of cyclophane $\mathbf{3}$ under a variety of different conditions afforded a total of five different bromides (Scheme 2 and Table 1).
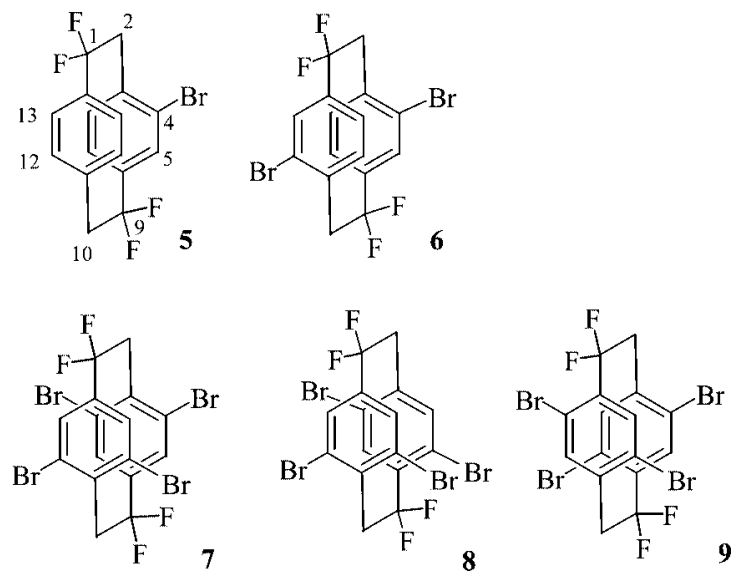

Scheme 2. Bromination products of 1,1,9,9-tetrafluoro[2.2.]paracyclophane 3.
Using the modified protocol by Cram, ${ }^{[9]}$ with excess bromine and $\mathrm{Fe}$ catalyst $\left(\mathrm{FeBr}_{3}\right.$ in situ), affords the monobromide $\mathbf{5}$ and only the pseudo-para-dibromide $\mathbf{6}$ in moderate to low yields, along with the polymer. This behavior is similar to cyclophane 1. In another experiment performed under light, a mixture of several highly brominated products were obtained, which were not fully characterized. Traces of triethylamine in the reaction mixture neutralize the acid present in the reaction and retard the bromination. Under these conditions, no polymer was formed and only the starting cyclophane was recovered. Without the iron catalyst and in spite of a great excess of bromine, only the starting material was recovered. When using the strongest and harshest bromination procedure employed by Dolbier et al. ${ }^{[10]}$ with $\mathrm{NBS} / \mathrm{TFA} / \mathrm{H}_{2} \mathrm{SO}_{4}$, three analogue isomers, the tetrabromide $\mathbf{8}$ with two minor isomers $\mathbf{7}$ and $\mathbf{9}$, were isolated in low yields. This procedure was not used for cyclophane 1, while cyclophane $\mathbf{2}$ afforded only the para-dibromide. ${ }^{[3 b]}$ Under the somewhat milder version of this procedure, ${ }^{[1]]}$ low yields of dibromide 6 were obtained. Selective conditions for the synthesis of monobromide $\mathbf{5}$ and dibromide $\mathbf{6}$ in high yields were observed - when pure bromine and a trace amount of iodine were used, i.e. König and de Meijere ${ }^{[12]}$ conditions previously used for preparation of tetrabromide isomers of cyclophane $\mathbf{1}$.

The bromides 6, 7, and 9 were characterized by MS, NMR spectroscopy, and X-ray structure analysis, which unambiguously revealed the structure of pseudo-para-dibromide $\mathbf{6}$ and the two tetrabromides 7 and 9 (Figure 1). Bromination of cyclophane $\mathbf{1}$ resulted in products analogous to bromides 6 and 9. It should also be noted that, although $\mathrm{X}$-ray analysis and mass spectrometry unambiguously reveals the structure of $7,{ }^{13} \mathrm{C}$ NMR spectroscopy is less conclusive, which can be attributed to the low amount of 7 available for the analysis.

The structural analysis of compound $\mathbf{8}$ was based on MS, elemental analysis, and NMR spectroscopy. Because of experimental difficulties in preparing adequate crystals, we were unable to conduct X-ray analysis. Nevertheless, a molecular weight of $596 \mathrm{~g} / \mathrm{mol}$ was detected by mass spectrometry, and the elemental analysis data clearly confirms $\mathbf{8}$ to be yet another tetrabromide isomer. The ${ }^{1} \mathrm{H}$ NMR spectrum of $\mathbf{8}$ reveals the presence of three aromatic protons at $\delta=7.23 \mathrm{ppm}(2 \mathrm{H}, 13-\mathrm{H}, 15-\mathrm{H}), 7.42 \mathrm{ppm}(1 \mathrm{H}, 8-\mathrm{H})$, and $7.53 \mathrm{ppm}(1 \mathrm{H}, 5-\mathrm{H})$. All aromatic protons appear as sing-

Table 1. Reaction conditions used for bromination of 1,1,9,9-tetrafluoro[2.2]paracyclophane (3).

\begin{tabular}{|c|c|c|c|c|c|c|c|c|}
\hline \multirow[t]{2}{*}{ Entry } & \multirow[t]{2}{*}{ Reagent $^{[\mathrm{a}]}$} & \multirow[t]{2}{*}{ Temp. $\left[{ }^{\circ} \mathrm{C}\right]$} & \multirow[t]{2}{*}{ Time } & \multicolumn{5}{|c|}{ Product yields $[\%]^{[\mathrm{b}]}$} \\
\hline & & & & 5 & 6 & 7 & 8 & 9 \\
\hline 1 & $\mathrm{Br}_{2} / \mathrm{Fe}, \mathrm{CCl}_{4}$ & 50 & $48 \mathrm{~h}$ & 33 & 2 & 0 & 0 & $0^{[\mathrm{c}]}$ \\
\hline 2 & $\mathrm{Br}_{2} / \mathrm{Fe} / \mathrm{CCl}_{4} / \mathrm{Et}_{3} \mathrm{~N}$ & 60 & $4 \mathrm{~d}$ & 21.7 & 0 & 0 & 0 & $0^{[\mathrm{d}]}$ \\
\hline 3 & $\mathrm{NBS}(3$ equiv. $) / \mathrm{TFA} / \mathrm{H}_{2} \mathrm{SO}_{4}$ & 23 & $24 \mathrm{~h}$ & 0 & 0 & 0.7 & 9.1 & $1.7^{[\mathrm{c}]}$ \\
\hline 4 & $\mathrm{NBS}(3$ equiv. $) / \mathrm{TFA} / \mathrm{H}_{2} \mathrm{SO}_{4} / \mathrm{CHCl}_{3}$ & 23 & $24 \mathrm{~h}$ & 0 & 7.9 & 0 & 0 & $0^{[\mathrm{c}]}$ \\
\hline 5 & $\mathrm{Br}_{2} / \mathrm{I}_{2}$ & 23 & $48 \mathrm{~h}$ & 72 & 0 & 0 & 0 & $0^{[\mathrm{c}]}$ \\
\hline 6 & $\mathrm{Br}_{2} / \mathrm{I}_{2}$ & 23 & $9 \mathrm{~d}$ & 33 & 45 & 0 & 0 & $0^{[\mathrm{c}]}$ \\
\hline 7 & $\mathrm{Br}_{2} / \mathrm{I}_{2}$ & 23 & 1 month & 0 & 65 & 0 & 0 & $0^{[\mathrm{c}]}$ \\
\hline
\end{tabular}

[a] All experiments were performed in the dark. [b] Yields refer to pure isolated products. [c] The rest is polymer. [d] The rest is recovered starting material $(65 \%)$. 


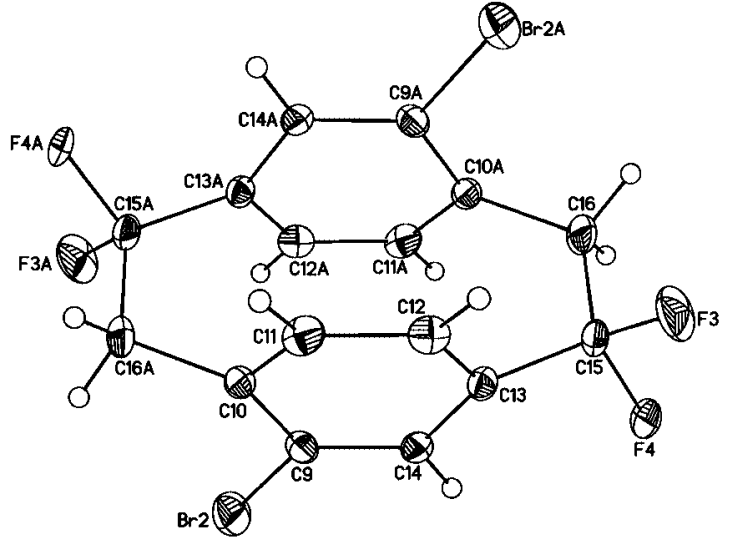

6

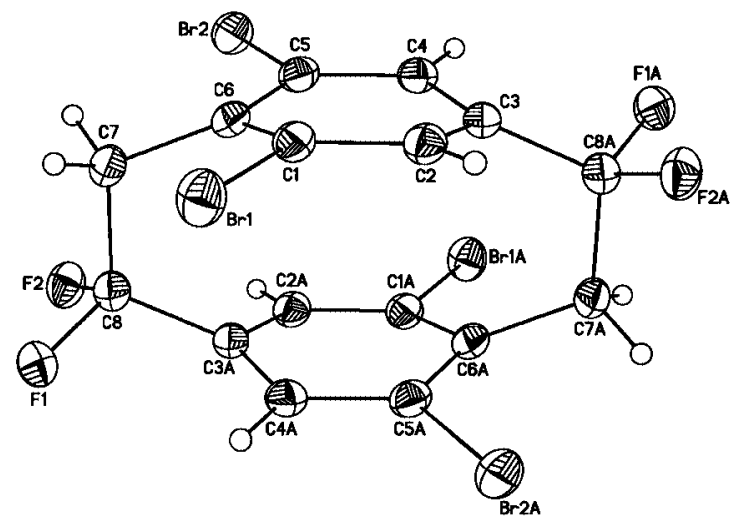

7

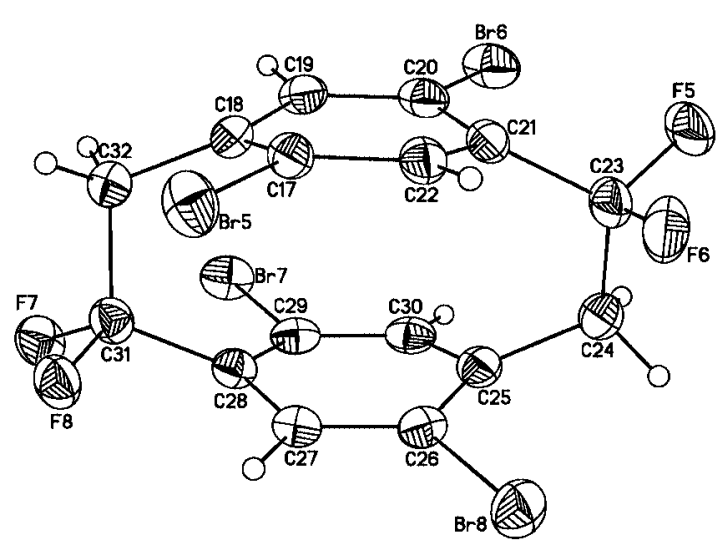

9

Figure 1. Molecular structures of bromide 6, 7 and 9 according to $\mathrm{X}$-ray crystal structure analysis.

lets, verifying that compound $\mathbf{8}$ is indeed 4,7,12,16-tetrabromo-1,1,9,9-tetrafluoro[2.2]paracyclophane. A closer look at the asymmetric paracyclophane bridges further support the assignment. The ${ }^{13} \mathrm{C}$ NMR spectrum of $\mathbf{8}$ reveals two different signals for the bridge carbons, indicating different substitution patterns on each ring. Moreover, the ${ }^{19} \mathrm{~F}$ NMR spectrum of $\mathbf{8}$ indicates the presence of three different fluorine species, as expected for a 4,7,12,16-tetrabromo1,1,9,9-tetrafluoro[2.2]paracyclophane. Taken together, these data provide overwhelming evidence that compound $\mathbf{8}$ is indeed the isomer with pseudo-geminal position of the bromides, as shown in Scheme 2. This finding was indeed somewhat unexpected, because direct pseudo-geminal bromation has not yet been observed for [2.2]paracyclophane (1). However, an indirect synthesis of all pseudo-geminal-dihalogenides has recently been reported, ${ }^{[13]}$ in spite the unfavorably close distance between the halogen atoms.

It is clear that the tetraflouro analogues have some unique chemical properties that distinguish them from [2.2]paracyclophane (1). During the bromination of the [2.2]paracyclophane $\mathbf{3}$, the bromine enters at the more favorable position, meta to the difluoromethylene group (i.e. ortho to the methylene group). This is in agreement with the fact that the trifluoromethyl group is deactivating and meta directing. ${ }^{[10]}$ The second bromine selectively attacks the pseudo-para position, resulting in dibromide 6. Halogens deactivate the aromatic rings and act as ortho and para directing groups. For the cyclophane 1, however, the third and the fourth bromine, only accessible under harsh conditions, enter the same ring at the ortho and para positions to yield only two tetrabromide isomers. ${ }^{[12]}$

Higher bromination of $\mathbf{6}$ yields two different tetrabromides $\mathbf{7}$ and $\mathbf{8}$. For the cyclophane 7, all bromides enter at the favorable meta position with respect to fluoromethylene groups. The very low yield of this reaction can be explained by a weaker inductive influence of the bridges toward the existing bromides. In the case of the compound $\mathbf{8}$, the entrance of one bromide is directed by fluoromethylene bridge while the other is directed by the influence of the preceding bromine, resulting in a mixed isomer with the bromides in pseudo-geminal position. The isomer $\mathbf{9}$, however, can not be originating from the dibromide $\mathbf{6}$, but from a pseudo-orthodibromide, which has not yet been observed, nor isolated. The fluoromethylene bridges direct the entrance of the first two bromides, while subsequent substitutions are directed by the foregoing bromines into the para position.

In contrast to compound $\mathbf{3}$, cyclophane $\mathbf{4}$ acts as a chemical hybrid of [2.2]paracyclophanes $\mathbf{1}$ and 2: It has one benzene ring with two para-difluoromethylene carbon atoms, which should have a low reactivity similar to that of the octafluoro[2.2]paracyclophane (2), while the other benzene ring behaves more like that of [2.2]paracyclophane (1). Since we observed the polymerization tendency of the cyclophane 3, we started with what we perceived to be the best reaction conditions for bromination of cyclophane 4 . Bromination of cyclophane $\mathbf{4}$ in pure bromine with catalytic amounts of iodine affords the para-dibromo isomer $\mathbf{1 1}$ as a major product $(\approx 70 \%)$ and a second minor product, possibly the monobromo compound $\mathbf{1 0}$, which has not been isolated (Scheme 3). The structure of the main product $\mathbf{1 1}$ was confirmed by X-ray structure analysis (Figure 2). Moreover, the results obtained by mass spectrometry clearly confirm the structure of $\mathbf{1 1}$ obtained by X-ray structure analysis, specifically, the fact that both bromine atoms enter the same aromatic ring. 


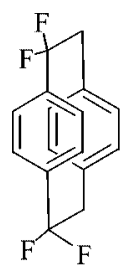

4

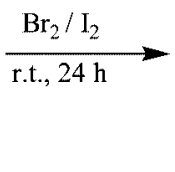

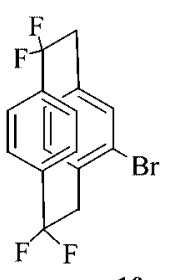

10

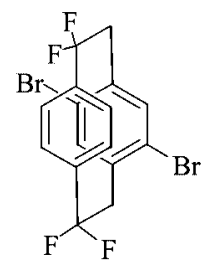

$1170 \%$
Scheme 3. Bromination products of 1,1,10,10-tetrafluoro[2.2.]paracyclophane (4).

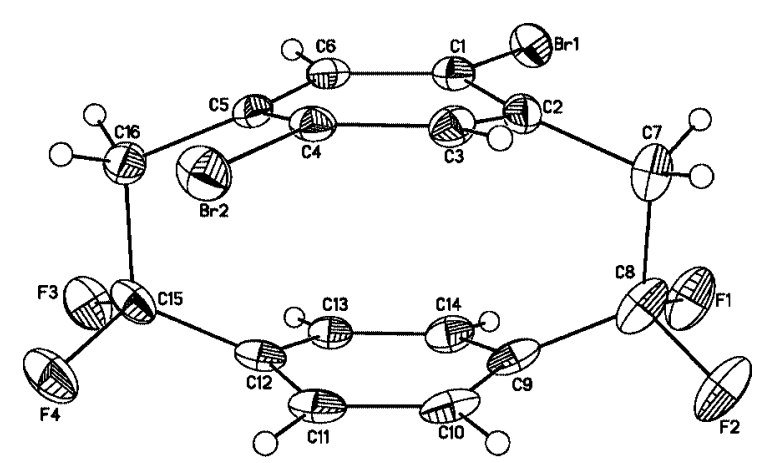

Figure 2. Molecular structure of dibromide $\mathbf{1 1 .}$

The interconversion equilibrium ${ }^{[14]}$ of the pseudo-paraand pseudo-ortho-dibromide isomers of [2.2]paracyclophanes (1) was first observed by Cram, and later used as an important step for the preparation of [2.2]PHANEPHOS catalyst systems ${ }^{[15 a]}$ and pseudo-ortho-ethynyl[2.2]paracyclophanes. ${ }^{[15 b]}$ We conducted the thermolysis of dibromocyclophane $\mathbf{6}$ under the same reaction conditions to those reported in the literature and also repeated it in a sealed tube at higher temperature. Both reactions resulted in the formation of an insoluble polymer (Scheme 4).<smiles>FC1(F)Cc2c(Br)cc(C(F)(F)F)c(Br)c2C1</smiles>

$$
\begin{aligned}
& \stackrel{\text { triglyme, reflux }}{\stackrel{236{ }^{\circ} \mathrm{C}, 18 \mathrm{~h}}{\longrightarrow}} \quad 90 \% \text { s.m. }+ \text { polymer } \\
& \text { sealed tube } \longrightarrow \\
& \stackrel{300{ }^{\circ} \mathrm{C}, 6 \mathrm{~h}}{\longrightarrow}
\end{aligned}
$$

Scheme 4. Thermal behavior of cyclophane $\mathbf{6}$.

The further investigation of the chemical reactivity of tetrafluoro[2.2]paracyclophanes and possibilities for functionalization of the mono and dibromo compounds will be carried out in due course.

In summary, we report here the bromination of the [2.2]paracyclophanes $\mathbf{3}$ and $\mathbf{4}$ as a new entry step towards the functionalized semifluorinated [2.2]paracyclophanes. The mono- and the dibromination of the cyclophane $\mathbf{3}$ is directed by the bridges, but further bromination depends on both the bridges as well as the preceding bromines. In spite of the deactivating character of this system, we found selective reaction conditions for the monobromide 5 and the dibromide $\mathbf{6}$ in high yields. We also prepared a mixture of tetrabromo isomers in low yields. The reactivity of the aromatic rings falls in between those of cyclophanes $\mathbf{1}$ and $\mathbf{2}$.
The cyclophane $\mathbf{4}$ being a hybrid molecule of cyclophane $\mathbf{1}$ and 2 afforded the para-dibromide in high yield. The resulting class of functionalized, semifluorinated [2.2]paracyclophanes could be of great interest for cyclophane chemistry and its application as vapor-based coatings, including surface modification of biomedical devices or biointerface design, thereby filling the gap between the non-fluorinated and perfluorinated analogues.

\section{Experimental Section}

General: ${ }^{1} \mathrm{H}$ and ${ }^{13} \mathrm{C}$ NMR spectra were recorded with a Varian Inova 400, ${ }^{1} \mathrm{H}$ NMR (400 MHz), ${ }^{13} \mathrm{C}$ NMR $(100.6 \mathrm{MHz}),{ }^{19} \mathrm{~F}$ NMR $(376 \mathrm{MHz})$ spectrometer. Chemical shifts $(\delta)$ are expressed in $\mathrm{ppm}$ downfield from tetramethylsilane using the residual nondeuterated solvent as internal standard $\left(\mathrm{CDCl}_{3}:{ }^{1} \mathrm{H}: \delta=7.22 ;{ }^{13} \mathrm{C}\right.$ : $\delta=77.00 \mathrm{ppm}$ ). Coupling constants are expressed in Hz. IR spectra were recorded with a Nicolet 6700 ATR spectrometer. Mass spectra were recorded with a VG (Micromass) 70-250-S Magnetic sector mass spectrometer $(\mathrm{EI}, 70 \mathrm{eV})$. Melting points are uncorrected. Thin layer chromatography was performed with silica gel precoated plastic plates from Baker, while column chromatography was performed on Silica gel 60. Preparative TLC was performed on TLC plates Silica gel $60 \mathrm{~F}_{254+366}, 2 \mathrm{~mm}$ from Merck.

General Bromination Procedure for 5, 6 and 11: ${ }^{[12]}$ Tetrafluoro[2.2]paracyclophane ( 1 or $2 \mathrm{mmol}$ ) was dissolved in $3-10 \mathrm{~mL}$ bromine and 1-2 small crystals of iodine were added. The loosely closed flask was wrapped in aluminium foil and left in the hood at room temp. for the time indicated in Table 1. The reaction was monitored by TLC in hexane/ $\mathrm{CH}_{2} \mathrm{Cl}_{2}, 7: 3$ and $9: 1$. The reaction mixture is then decomposed by careful addition of $20 \%$ aqueous $\mathrm{KOH}$ and by cooling. The mixture was transferred to a separating funnel, and extracted with $3 \times 15-30 \mathrm{~mL} \mathrm{CH}_{2} \mathrm{Cl}_{2}$. The collected organic solution was washed with brine and dried with anhydrous $\mathrm{Na}_{2} \mathrm{SO}_{4}$. The solution was filtered, and the solvent evaporated to dryness. The residue was purified by column chromatography on silica gel.

4-Bromo-1,1,9,9-tetrafluoro[2.2]paracyclophane (5): Colorless crystals; m.p. $123-124{ }^{\circ} \mathrm{C}$. IR (Ge-ATR): $\tilde{v}=2917$ (vw), 1652 (vw), 1427 (vw), 1405 (vw), 1325 (w), 1219 (vw), 1198 (vw), 1085 (w), 1053 (w), 873 (vw), 846 (w), 769 (s), 647 (w) $\mathrm{cm}^{-1} .{ }^{1} \mathrm{H}$ NMR (400 MHz, $\left.\mathrm{CDCl}_{3}\right): \delta=3.40$ (dddd, $J=11.0 \mathrm{~Hz}, 1 \mathrm{H}$ ), 3.50-3.65 $(\mathrm{m}, 2 \mathrm{H}), 4.06\left(\mathrm{dt}, J_{1}=10.4, J_{1}=15.6 \mathrm{~Hz}, 1 \mathrm{H}\right), 6.65\left(\mathrm{~d}, J_{1}=\right.$ $7.7 \mathrm{~Hz}, 1 \mathrm{H}) 6.67(\mathrm{~d}, J=6.6 \mathrm{~Hz}, 1 \mathrm{H}), 6.77-6.84(\mathrm{~m}, 3 \mathrm{H}), 6.89$ (s, $1 \mathrm{H}), 7.39(\mathrm{~d}, J=8.1 \mathrm{~Hz}, 1 \mathrm{H}) \mathrm{ppm} .{ }^{13} \mathrm{C} \mathrm{NMR}(100.6 \mathrm{MHz}$, $\left.\mathrm{CDCl}_{3}\right): \delta=50.57(\mathrm{t}, J=35.1 \mathrm{~Hz}), 51.06(\mathrm{t}, J=32.8), 125.02(\mathrm{dd}$, $J=4.6 \mathrm{~Hz}), 128.20(\mathrm{dd}, J=5.8 \mathrm{~Hz}), 129.45(\mathrm{t}, J=5.8 \mathrm{~Hz}), 133.03$ (s), $133.50(\mathrm{dd}, J=5.0 \mathrm{~Hz}), 133.83(\mathrm{~s}), 135.73(\mathrm{~s}) \mathrm{ppm} .{ }^{19} \mathrm{~F}$ NMR $\left(376 \mathrm{MHz}, \mathrm{CDCl}_{3}\right): \delta=-89.03(\mathrm{dd}, J=10.7 \mathrm{~Hz}, 1 \mathrm{~F}),-89.15(\mathrm{dd}$, $J=10.7 \mathrm{~Hz}, 1 \mathrm{~F}),-91.81(\mathrm{dd}, J=10.7 \mathrm{~Hz}, 1 \mathrm{~F}),-92.17(\mathrm{dd}, J=$ $11.6 \mathrm{~Hz}, 1 \mathrm{~F}) \mathrm{ppm}$. MS $(70 \mathrm{eV}): m / z(\%)=360(50)\left[\mathrm{M}^{+}\right], 314(18)$ $\left[\mathrm{M}^{+}-\mathrm{C}_{2} \mathrm{H}_{3} \mathrm{~F}\right], 218$ (36) $\left[\mathrm{C}_{8} \mathrm{H}_{5} \mathrm{~F}_{2} \mathrm{Br}\right], 140$ (100) $\left[\mathrm{C}_{8} \mathrm{H}_{6} \mathrm{~F}_{2}\right]$. $\mathrm{C}_{16} \mathrm{H}_{11} \mathrm{BrF}_{4}$ (359.16): calcd. C 53.51, H 3.09; found C 53.80, H 2.45 .

4,12-Dibromo-1,1,9,9-tetrafluoro[2.2]paracyclophane (6): Colorless crystals; m.p. $172-173{ }^{\circ} \mathrm{C}$. IR (Ge-ATR): $\tilde{v}=2923$ (vw), 1733 (vw), 1540 (vw), 1426 (vw), 1384 (w), 1323 (m), 1217 (w), 1201(w), 1087 (m), 1055 (m), 1033(w), 873 (w), 843 (m), 784 (s), 739 (vs) cm cm. $^{-1}$ ${ }^{1} \mathrm{H}$ NMR (400 MHz, $\mathrm{CDCl}_{3}$ ): $\delta=3.38$ (dddd, $J=10.8 \mathrm{~Hz}, 2 \mathrm{H}$ ), $4.08\left(\mathrm{dt}, J_{1}=10.8, J_{2}=16.0 \mathrm{~Hz}, 2 \mathrm{H}\right), 6.62(\mathrm{~d}, J=8.1 \mathrm{~Hz}, 2 \mathrm{H})$, $6.93(\mathrm{~s}, 2 \mathrm{H}), 7.33$ (d, $J=8.4 \mathrm{~Hz}, 2 \mathrm{H}) \mathrm{ppm} .{ }^{13} \mathrm{C} \mathrm{NMR}(100.6 \mathrm{MHz}$, $\left.\mathrm{CDCl}_{3}\right): \delta=50.56(\mathrm{t}, J=34.7 \mathrm{~Hz}), 124.45(\mathrm{dd}, J=4.2 \mathrm{~Hz}), 127.74$ 
(s), $133.33(\mathrm{t}, J=5.7 \mathrm{~Hz}), 135.79$ (s) ppm. ${ }^{19} \mathrm{~F}$ NMR $(376.3 \mathrm{MHz}$, $\left.\mathrm{CDCl}_{3}\right): \delta=-89.50(\mathrm{dd}, J=10.7 \mathrm{~Hz}, 2 \mathrm{~F}),-89.305(\mathrm{dd}, J=9.2 \mathrm{~Hz}$, $2 \mathrm{~F}) \mathrm{ppm}$. MS $(70 \mathrm{eV}): m / z(\%)=438(30)\left[\mathrm{M}^{+}\right], 394(14)\left[\mathrm{M}^{+}-\right.$ $\left.\mathrm{C}_{2} \mathrm{HF}\right], 218$ (100) [1/2 $\left.\mathrm{M}^{+}\right], 174$ (34) [1/2 $\left.\mathrm{M}^{+}-\mathrm{C}_{2} \mathrm{HF}\right]$. HRMS (EI): $m / z\left[\mathrm{M}^{+}\right]$; found 435.9099; calculated for $\mathrm{C}_{16} \mathrm{H}_{10} \mathrm{Br}_{2} \mathrm{~F}_{4}$ 435.9085. 5 $\left(\mathrm{C}_{16} \mathrm{H}_{10} \mathrm{~F}_{4} \mathrm{Br}_{2}\right) \cdot \mathrm{C}_{6} \mathrm{H}_{14}$ (2276.46): calcd. $\mathrm{C} 45.38, \mathrm{H} 2.83$; found $\mathrm{C}$ 46.13, H 2.39 .

Preparation of Tetrabromides 7, 8 and 9: ${ }^{[10]}$ NBS (1.08 g, $\left.6 \mathrm{mmol}\right)$ was added in several portions over $12 \mathrm{~h}$ to a solution of $3(560 \mathrm{mg}$, $2 \mathrm{mmol}$ ) in $2 \mathrm{~mL}$ trifluoroacetic acid and $0.8 \mathrm{~mL}$ sulfuric acid. The reaction mixture was stirred at room temp. overnight. The reaction was monitored by TLC in hexane/ $\mathrm{CH}_{2} \mathrm{Cl}_{2}$ (7:3 and 9:1), indicating the formation of polymer at the starting point and very little products. The reaction mixture was poured onto ice water and extracted with $\mathrm{CH}_{2} \mathrm{Cl}_{2}(3 \times 10 \mathrm{~mL})$. The combined organic layer (suspension of polymer) was washed with water, $\mathrm{NaHCO}_{3}$, brine and dried with anhydrous $\mathrm{Na}_{2} \mathrm{SO}_{4}$. The solvent was evaporated to dryness. Purification by column chromatography on silica gel, eluted with hexane and hexane/dichloromethane (98:2), gave a mixture of 7 (27 mg), pure 8 (108 $\mathrm{mg}, 9.1 \%)$ and $9(20 \mathrm{mg}, 1.7 \%)$. The impure 7 was separated by preparative TLC in hexane to give pure $7(8 \mathrm{mg}$, $0.7 \%)$.

4,8,12,16-Tetrabromo-1,1,9,9-tetrafluoro[2.2]paracyclophane (7): Colorless crystals; m.p. ca. $290^{\circ} \mathrm{C}$ (decomposition). IR (Ge-ATR): $\tilde{v}=2922(\mathrm{vw}), 1376(\mathrm{vw}), 1326(\mathrm{vw}), 1244(\mathrm{vw}), 1090(\mathrm{vw}), 1058$ (vw), 875 (vw), 826 (vw), 786 (vs), 754 (vs), 695 (vw) $\mathrm{cm}^{-1} \cdot{ }^{1} \mathrm{H}$ NMR (400 MHz, CDCl $): \delta=4.00(\mathrm{t}, J=13.1 \mathrm{~Hz}, 4 \mathrm{H}), 7.45(\mathrm{~s}, 4$ $\mathrm{H})$ ppm. ${ }^{13} \mathrm{C} \mathrm{NMR}\left(100.6 \mathrm{MHz}, \mathrm{CDCl}_{3}\right): \delta=49.97(\mathrm{t}, J=35.1 \mathrm{~Hz})$, $128.21,128.27,128.33,128.60,136.35 \mathrm{ppm} .{ }^{19} \mathrm{~F}$ NMR $(376.3 \mathrm{MHz}$, $\left.\mathrm{CDCl}_{3}\right): \delta=-87.33(\mathrm{t}, J=13.0 \mathrm{~Hz}, 4 \mathrm{~F}) \mathrm{ppm}$. MS $(70 \mathrm{eV}): \mathrm{m} / \mathrm{z}(\%)$ $=595.9$ (91) $\left[\mathrm{M}^{+}\right], 485.7$ (11), 298.0 (100) $\left[1 / 2 \mathrm{M}^{+}\right], 138.1$ (58). HRMS (EI): $\mathrm{m} / z\left[\mathrm{M}^{+}\right]$found 591.7286; calculated. for $\mathrm{C}_{16} \mathrm{H}_{8} \mathrm{Br}_{4} \mathrm{~F}_{4}$ 591.7296.

4,7,12,16-Tetrabromo-1,1,9,9-tetrafluoro|2.2]paracyclophane (8): Colorless crystals; m.p. $150-152^{\circ} \mathrm{C}$. IR (Ge-ATR): $\tilde{v}=3050$ (vw), 1551 (vw), 1510 (vw), 1479 (vw), 1428 (w), 1384 (w), 1338 (m), 1324 (s), 1311 (s), 1218 (m), 1207 (m), 1116 (vs), 1087 (vs), 1078 (vs), 1069 (vs), 878 (s), 868 (m) cm $\left.{ }^{-1} .{ }^{1} \mathrm{H} \mathrm{NMR} \mathrm{(400} \mathrm{MHz,} \mathrm{CDCl}_{3}\right)$ : $\delta=3.48(\mathrm{ddd}, J=17.4 \mathrm{~Hz}, 1 \mathrm{H}), 3.92(\mathrm{dt}, J=4.8, J=14.0 \mathrm{~Hz}, 1$ H), 4.10 (ddd, $J=8.3, J=9.9 \mathrm{~Hz}, 2 \mathrm{H}), 7.23$ (s, $2 \mathrm{H}), 7.42$ (s, 1 $\mathrm{H}), 7.53(\mathrm{~s}, 1 \mathrm{H}) \mathrm{ppm} .{ }^{13} \mathrm{C} \mathrm{NMR}\left(100.6 \mathrm{MHz}, \mathrm{CDCl}_{3}\right): \delta=47.61$ $(\mathrm{t}, J=31.3 \mathrm{~Hz}), 51.92(\mathrm{t}, J=35.5 \mathrm{~Hz}), 123.25(\mathrm{dd}, J=3.8 \mathrm{~Hz})$, $128.92(\mathrm{dd}, J=3.8 \mathrm{~Hz}), 130.90$ (dd, $J=6.8 \mathrm{~Hz}), 131.84$ (s) ppm. ${ }^{19} \mathrm{~F}$ NMR $\left(376.3 \mathrm{MHz}, \mathrm{CDCl}_{3}\right): \delta=-82.24$ (ddd, $J=4.6 \mathrm{~Hz}, 1$ F), -82.27 (d, $J=30.5 \mathrm{~Hz}, 1 \mathrm{~F}),-85.54(\mathrm{ddq}, J=7.6, J=10.7, J$ $=232 \mathrm{~Hz}, 2 \mathrm{~F})$ ppm. MS $(70 \mathrm{eV}): \mathrm{m} / z(\%)=596.0(29)\left[\mathrm{M}^{+}\right], 516.0$ (8) $\left[\mathrm{M}^{+}-\mathrm{Br}\right], 375.9$ (9), 298.0 (17) $\left[1 / 2 \mathrm{M}^{+}\right], 218.0(100)\left[1 / 2 \mathrm{M}^{+}-\right.$ Br]. $\mathrm{C}_{16} \mathrm{H}_{8} \mathrm{Br}_{4} \mathrm{~F}_{4}$ (595.85): calcd. C $32.25, \mathrm{H} \mathrm{1.35}$; found $\mathrm{C} 32.85$, $\mathrm{H} 1.55$.

4,7,13,16-Tetrabromo-1,1,9,9-tetrafluoro[2.2]paracyclophane (9): Colorless crystals; m.p. $187-189^{\circ} \mathrm{C}$. IR (Ge-ATR): $\tilde{v}=1463$ (vw), 1425 (vw), 1356 (w), 1304 (w), 1316 (w), 1230 (vw), 1188 (w), 1101 (m), 1075 (m), 1063 (w), 1014 (w), 899 (w), 754 (vs) cm ${ }^{-1} .{ }^{1} \mathrm{H}$ NMR (400 MHz, $\mathrm{CDCl}_{3}$ ): $\delta=3.42(\mathrm{ddd}, J=17.6 \mathrm{~Hz}, 2 \mathrm{H}$ ), 3.86 (dddd, $J=10.0 \mathrm{~Hz}, 2 \mathrm{H}), 7.45(\mathrm{~s}, 2 \mathrm{H}), 7.46(\mathrm{~s}, 2 \mathrm{H}) \mathrm{ppm} .{ }^{13} \mathrm{C} \mathrm{NMR}$ $\left(100.6 \mathrm{MHz}, \mathrm{CDCl}_{3}\right): \delta=47.08(\mathrm{t}, J=32.0 \mathrm{~Hz}), 128.48(\mathrm{~m}), 132.06$ (t, $J=8.4 \mathrm{~Hz}), 134.71(\mathrm{~s}), 137.496$ (s) ppm. ${ }^{19} \mathrm{~F}$ NMR $(376.3 \mathrm{MHz}$, $\left.\mathrm{CDCl}_{3}\right): \delta=-83.17(\mathrm{~d}, J=9.2 \mathrm{~Hz}, 2 \mathrm{~F}),-83.21(\mathrm{dd}, J=4.6, J=$ $16.0 \mathrm{~Hz}, 2 \mathrm{~F}) \mathrm{ppm}$. MS $(70 \mathrm{eV}): \mathrm{m} / z(\%)=596.0(50)\left[\mathrm{M}^{+}\right], 516.1$

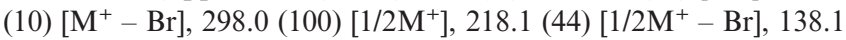
(44) $\left[1 / 2 \mathrm{M}^{+}-2 \mathrm{Br}\right]$. HRMS (EI): $m / z\left[\mathrm{M}^{+}\right]$found 591.7299; calculated. for $\mathrm{C}_{16} \mathrm{H}_{8} \mathrm{Br}_{4} \mathrm{~F}_{4} 591.7296$.
4,7-Dibromo-1,1,10,10-tetrafluoro[2.2]paracyclophane (11): Colorless crystals; m.p. $112-113{ }^{\circ} \mathrm{C}$. IR (ZnSe-ATR): $\tilde{v}=2941$ (w), 1917 (w), $1464(\mathrm{w}), 1428(\mathrm{w}), 1390(\mathrm{w}), 1324$ (s), $1224(\mathrm{w}), 1193(\mathrm{w})$, 1095 (s), 1060 (m), 1033 (m), 999 (m), 950 (w), 878 (w), 844 (m) $\mathrm{cm}^{-1} .{ }^{1} \mathrm{H}$ NMR $\left(400 \mathrm{MHz}, \mathrm{CDCl}_{3}\right): \delta=3.32(\mathrm{q}, J=14.3 \mathrm{~Hz}, 2 \mathrm{H})$, 3.98 (q, $J=13.6 \mathrm{~Hz}, 2 \mathrm{H}), 6.62(\mathrm{~s}, 2 \mathrm{H}), 6.90(\mathrm{~d}, J=8.4 \mathrm{~Hz}, 2 \mathrm{H})$, $7.55(\mathrm{~d}, J=8.1 \mathrm{~Hz}, 2 \mathrm{H}) \mathrm{ppm} .{ }^{13} \mathrm{C} \mathrm{NMR}\left(100.6 \mathrm{MHz}, \mathrm{CDCl}_{3}\right): \delta$ $=49.67(\mathrm{t}, J=34.7 \mathrm{~Hz}), 122.61(\mathrm{~s}), 125.25(\mathrm{t}, J=5.7 \mathrm{~Hz}), 126.13$ (s), $127.73(\mathrm{~s}), 128.93(\mathrm{t}, J=6.1 \mathrm{~Hz}), 136.32(\mathrm{t}, J=27.1 \mathrm{~Hz}), 138.17$ (t, $J=5.3 \mathrm{~Hz}), 138.74$ (s) ppm. ${ }^{19} \mathrm{~F}$ NMR (376.3 MHz, $\left.\mathrm{CDCl}_{3}\right): \delta$ $=-89.152(\mathrm{t}, J=14.1 \mathrm{~Hz}, 4 \mathrm{~F}) \mathrm{ppm}$. MS $(70 \mathrm{eV}): \mathrm{m} / \mathrm{z}(\%)=438.0$ (45) $\left[\mathrm{M}^{+}\right], 419.0(5)\left[\mathrm{M}^{+}-\mathrm{F}\right], 261.9$ (5) $\left[\mathrm{C}_{8} \mathrm{H}_{6} \mathrm{Br}_{2}{ }^{+}\right], 176.0$ (100) $\left[\mathrm{C}_{8} \mathrm{H}_{4} \mathrm{~F}_{4}{ }^{+}\right], 126.0$ (20), 102.1 (15).

X-ray Crystallography Data Collection and Structure Refinement for 6,7, 9 and 11: All data were collected with a Bruker Platform Diffractometer with $1 \mathrm{~K} \mathrm{CCD}$ area detector and LT-2 low temperature device using graphite-monochromated Mo- $K_{\alpha}$ radiation. The structures were solved using direct methods and refined using Fourier techniques (G. M. Sheldrick, SHELXTL, v. 6.12; Bruker Analytical X-ray, Madison, WI, 2001). All non-hydrogen atoms were allowed to refine anisotropically, and the hydrogen atoms were placed in idealized positions using a rigid model. CCDC-600896 (6), -600897 (7), -600898 (9), and -600899 (11) contain the supplementary crystallographic data for this paper. These data can be obtained free of charge from The Cambridge Crystallographic Data Centre via www.ccdc.cam.ac.uk/data_request/cif.

\section{Acknowledgments}

This work was supported by the NSF in the form of a CAREER grant (DMR-0449462) and the funding from the NSF under the MRI program (DMR 0420785).

[1] a) Reviews: R. Gleiter, H. Hopf, Modern Cyclophane Chemistry, Wiley-VCH Weinheim 2004 b) H. Hopf, Classics in Hydrocarbon Chemistry, Wiley-VCH, Weinheim, 2000, Ch.12.3. 337378; c) F. Vögtle, Cyclophane Chemistry, Wiley, VCH, Chichester 1993.

[2] W. R. Dolbier Jr, X. X. Rong, Y. Xu, J. Org. Chem. 1997, 62, $7500-7502$.

[3] a) A. J. Roche, W. R. Dolbier Jr, J. Org. Chem. 1999, 64, 9137 9143; b) A. J. Roche, W. R. Dolbier Jr, J. Org. Chem. 2000, 65, 5282-5290; c) M. A. Battiste, J.-X. Duan, Y.-A. Zhai, I. Ghiviriga, K. A. Abboud, W. R. Dolbier Jr, J. Org. Chem. 2003, 68, 3078-3083; d) Y. Zhai, I. Ghiviriga, M. A. Battiste, W. R. Dolbier Jr, Synthesis 2004, 2747-2750.

[4] a) M. Stöbbe, O. Reiser, R. Näder, A. de Meijere, Chem. Ber. 1987, 120, 1667-1674; b) A. Dávila, J. O. Escobedo, M. W. Read, F. R. Fronczek, R. M. Strongin, Tetrahedron Lett. 2001, 42, 3555-3557.

[5] a) S. Teshima, Y. Asako, JP 2001031598, 2001 [Chem. Abstr., 134:147413]; b) H. Maruyama, JP 09025252, 1997 [Chem. Abstr. 126:225652]; c) T. Itoh, S. Okuoka, M. Kubo, S. Iwatsuki, J. Polym. Sci., Part A: Polymer Chemistry 1995, 33, 359363.

[6] a) H. Kinomoto, T. Mochizuki, JP 2000003909, 2000 [Chem Abstr. 132:72206]; b) H. Maruyama, EP 856503, 1998 [Chem. Abstr. 129:176997]; c) H. Maruyama JP 10195181, 1998 [Chem. Abstr. 129:162578]; d) H. Maruyama, JP 09059187, 1997 [Chem. Abstr. 126:306291].

[7] a) D. J. Cram, H. P. Fischer, J. Org. Chem. 1965, 30, 1815-1819; b) D. J. Cram, R. C. Heigeson, D. Lock, L. A. Singer, J. Am. Chem. Soc. 1966, 88, 1324-1325.

[8] a) J. Porwisiak, M. Schlosser, Chem. Ber. 1996, 129, 233-235; b) X. Creary, J. Org. Chem. 1987, 52, 5026-5030; c) A. Cipici- 
ani, F. Fringuelli, V. Mancini, O. Piermatti, F. Pizzo, R. Ruzziconi, J. Org. Chem. 1997, 62, 3744-3747; d) A. de Meijere, F. Diederich, Meatal-Catalyzed Cross-Coupling Reactions, 2nd ed., Wiley-VCH, Weinheim, 2004.

[9] H. J. Reich, D. J. Cram, J. Am. Chem. Soc. 1969, 91, 35053516.

[10] L. H. Zhang, W. R. Dolbier Jr, Synlett 1999, 1245.

[11] H. Eguchi, H. Kawaguchi, S. Yoshinaga, A. Nishida, T. Nishiguchi, S. Fujisaki, Bull. Chem. Soc. Jpn. 1994, 67, 1918-1921.

[12] B. König, B. Knieriem, A. de Meijere, Chem. Ber. 1993, 126, $1643-1650$.
[13] K. El Saib, V. Narayanan, H. Hopf, I. Dix, A. Fiescher, P. G. Jones, L. Ernst, K. Ibrom, Eur. J. Org. Chem. 2003, 567-577.

[14] H. J. Reich, D. J. Cram, J. Am. Chem. Soc. 1969, 91, 35173526.

[15] a) P. J. Pye, K. Rossen, R. A. Reamer, N. N. Tsou, R. P. Volante, P. J. Reider, J. Am. Chem. Soc. 1997, 119, 6207; b) L. Bondarenko, I. Dix, H. Hinrichs, H. Hopf, Synthesis 2004, 2751-2759.

Received: July 12, 2006

Published Online: October 19, 2006 